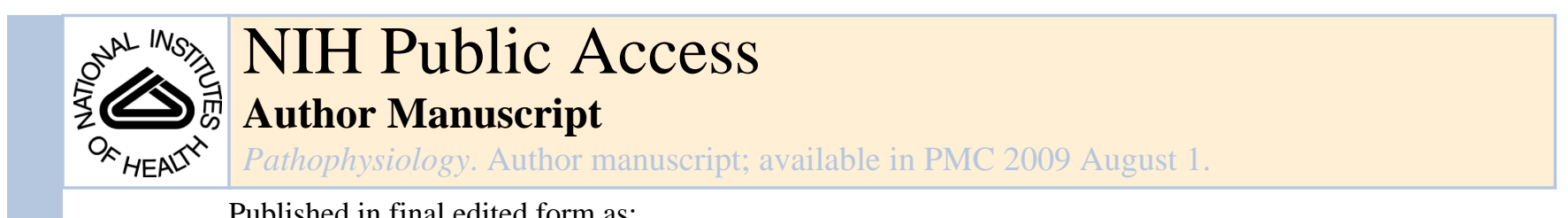

Published in final edited form as:

Pathophysiology. 2008 August ; 15(2): 69-70. doi:10.1016/j.pathophys.2008.04.006.

\title{
Pathophysiology of Obesity
}

\author{
Chantal A. Rivera, PhD \\ Department of Molecular \& Cellular Physiology, LSU Health Sciences Center-Shreveport
}

\begin{abstract}
Whereas under-nutrition produced much of the illness and mortality that plagued preindustrialized nations, modernization has replaced starvation with obesity as a major risk factor for disease. In the United States obesity is defined as a body mass index (BMI) of greater than $30 \mathrm{~kg} / \mathrm{m}^{2}$. Less than $15 \%$ of the US population was obese in 1985 . Today the prevalence of overweight and obesity in this country is now estimated to exceed $60 \%$ of the general population $(2 ; 4)$ and the prevalence of obesity is increasing at a rate of about $1 \%$ annually.
\end{abstract}

The degree of adiposity in humans is attributed primarily to physical inactivity and excessive caloric intake. As a result, recent investigations have focused on elucidating the contribution of diet to the development of systemic pathologies. A positive correlation exists between the incidence of metabolic syndrome and the amount of total fat consumed in the diet of obese humans. The components of a typical "western" diet (WD) include high amounts of saturated fat, cholesterol and sucrose. Cholesterol and saturated fatty acids have been linked to activation of pro-inflammatory signaling cascades in cultured macrophages (3). These results are supported by findings in vivo of inflammation and endothelial dysfunction in baboons fed a high cholesterol/high saturated fat diet (5).

It is believed that adipose tissue, specifically abdominal adiposity, plays a key role in the chronic inflammatory state associated with obesity, most likely via the enhanced production of adipose-derived cytokines, now referred to as adipokines. This special issue of Pathophysiology highlights the growing recognition that obesity results in a systemic inflammatory response that enhances the relative risk of developing chronic illness. Dr. Jeff Frisbee and colleagues have reviewed the influence of chronic obesity on various aspects of vascular function, including vascular reactivity, vessel wall structure and organ perfusion. Adaptations to adiposity, peri-vascular adipose tissue, as well as the benefits of weight reduction are discussed.

Research in my own laboratory has focused on a form of liver disease associated with chronic obesity known as non-alcoholic steatohepatitis (NASH). Thus, my contribution to this issue is a review of common risk factors associated with NASH. Adiposity, the existence of type 2 diabetes and race/ethnicity seem to provide the strongest correlations with disease severity. Recent findings suggesting a role for pattern recognition receptors, endotoxin and dietary lipids as mediators of NASH are summarized. A fraction of NASH patients will progress to some degree of fibrotic lesions in the liver. Dr. Fabio Marra and colleagues provide an overview of the fibrogenic process and summarize the pathological significance of excessive amounts of adipose tissue. Data collected from animal models and

(C) 2008 Elsevier Ireland Ltd. All rights reserved.

Publisher's Disclaimer: This is a PDF file of an unedited manuscript that has been accepted for publication. As a service to our customers we are providing this early version of the manuscript. The manuscript will undergo copyediting, typesetting, and review of the resulting proof before it is published in its final citable form. Please note that during the production process errors may be discovered which could affect the content, and all legal disclaimers that apply to the journal pertain. 
humans that describe the roles played by adipokines such as leptin, adiponectin and resistin on stellate cell activation and the subsequent induction of fibrosis are outlined. In the article contributed by Dr. Kevin Pruitt and co-worker, the role of the histone deacetylase SIRT1 in the regulation of adiposity and adipokine expression is examined, which provides an interesting view of how epigenetics play a role in survival during calorie restriction as well as energy homeostatis during periods of nutrient abundance.

Although cardiovascular responses and liver disease have been examined extensively, much less attention has been given to other co-morbid conditions of obesity such as obstructive sleep apnea (OSA) and adverse female reproductive health. Dr. Robert Carter et al. explore the complex relationship between obesity and OSA. Although it is well established that the prevalence and severity of OSA are enhanced among obese individuals, Dr. Carter reviews interesting new findings that OSA may also enhance overweight status via adversely affecting energy metabolism and daytime activity patterns. Another underrecognized co-morbidity of obesity is aberrant reproductive health in females. Dr. Rebecca

Robker provides a concise and informative review of the pathologies resulting in inadequate reproductive physiology in obese females. Results detailed in this review demonstrate the relationship between diminished oocyte integrity, fertility and enhanced miscarriage rates among this patient population. Moreover, Dr. Robker's research with insulin sensitizing pharmaceuticals suggests that PPAR $\gamma$ may be a key regulator of oocyte quality.

Not only does obesity increase the risk of developing illnesses such as liver disease and OSA, this condition also appears to worsen outcomes following trauma and surgery. Dr. Vidula Vachharajani has highlighted the impact of obesity on morbidity and mortality among critically ill patients. Data presented suggests that poor outcome in this patient population is related to the chronic, low-grade inflammatory condition that is exaggerated by overweight status.

A decrease in BMI will ameliorate or eliminate many of the complications of morbid obesity, even prior to achievement of ideal body weight. Due to the relative ineffectiveness of most pharmacological and behavioral therapies, surgical weight loss procedures are now more common than ever, with more than 40,000 procedures performed in American adults each year. As a result of the increasing prevalence of obesity in adolescent individuals, which puts them at greater risk of developing "adult-like" life-threatening comorbidities (e.g. type 2 diabetes and cardiovascular disease), pediatric surgeons are now considering surgery as an appropriate treatment option for morbidly obese children. Dr. Stavra Xanthakos has contributed an article that describes the types of bariatric surgeries that are performed and indications for the use of surgical procedures in children. Similar to adults, outcome following bariatric surgery in adolescents include significant weight reduction, diminished pre-surgical co-morbid conditions, and improved glycemic control. Dr. Xanthakos also describes the impact of surgery on gut-derived hormones that control appetite.

As a result of the impact of weight status on health, Americans spend more than 117 billion dollars annually on healthcare related to obesity and it is estimated that there are between 200,000 and 341,000 obesity-associated deaths each year in the US (1). Clearly, research investigating mechanisms underlying obesity-associated illnesses is needed and has the potential to benefit a significant proportion of the population in the United States and worldwide. I would like to commend the contributing authors for their efforts toward producing this special issue and for their research on this biomedical problem of international consequence. 


\section{Reference List}

1. Allison DB, Fontaine KR, Manson JE, Stevens J, VanItallie TB. Annual deaths attributable to obesity in the United States. JAMA 1999;282:1530-1538. [PubMed: 10546692]

2. Kuczmarski RJ, Flegal KM, Campbell SM, Johnson CL. Increasing prevalence of overweight among US adults. The National Health and Nutrition Examination Surveys, 1960 to 1991. JAMA 1994;272:205-211. [PubMed: 8022039]

3. Lee JY, Ye J, Gao Z, Youn HS, Lee WH, Zhao L, Sizemore N, Hwang DH. Reciprocal modulation of Toll-like receptor-4 signaling pathways involving MyD88 and phosphatidylinositol 3-kinase/ AKT by saturated and polyunsaturated fatty acids. J Biol Chem 2003;278:37041-37051. [PubMed: 12865424]

4. Mokdad AH, Serdula MK, Dietz WH, Bowman BA, Marks JS, Koplan JP. The spread of the obesity epidemic in the United States, 1991-1998. JAMA 1999;282:1519-1522. [PubMed: 10546690]

5. Shi Q, Vandeberg JF, Jett C, Rice K, Leland MM, Talley L, Kushwaha RS, Rainwater DL, Vandeberg JL, Wang XL. Arterial endothelial dysfunction in baboons fed a high-cholesterol, highfat diet. Am J Clin Nutr 2005;82:751-759. [PubMed: 16210703] 